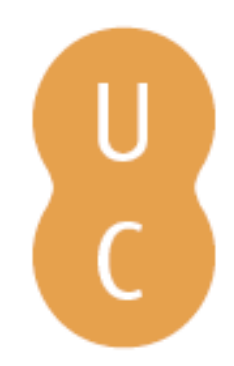

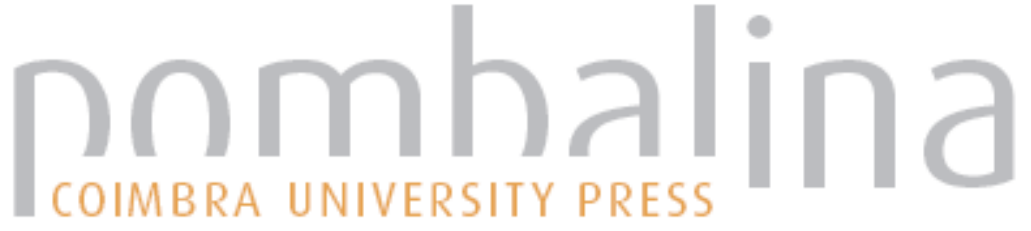

\section{Fenómenos paroxísticos, crises epiléticas e epilepsias}

\author{
Autor(es): $\quad$ Pereira, Cristina; Robalo, Conceição
}

Publicado por: Imprensa da Universidade de Coimbra

URL

persistente: $\quad$ URI:http://hdl.handle.net/10316.2/43141

DOI: $\quad$ DOI:https://doi.org/10.14195/978-989-26-1300-0_40

Accessed : $\quad$ 26-Apr-2023 01:33:42

A navegação consulta e descarregamento dos títulos inseridos nas Bibliotecas Digitais UC Digitalis, UC Pombalina e UC Impactum, pressupõem a aceitação plena e sem reservas dos Termos e Condições de Uso destas Bibliotecas Digitais, disponíveis em https://digitalis.uc.pt/pt-pt/termos.

Conforme exposto nos referidos Termos e Condições de Uso, o descarregamento de títulos de acesso restrito requer uma licença válida de autorização devendo o utilizador aceder ao(s) documento(s) a partir de um endereço de IP da instituição detentora da supramencionada licença.

Ao utilizador é apenas permitido o descarregamento para uso pessoal, pelo que o emprego do(s) título(s) descarregado(s) para outro fim, designadamente comercial, carece de autorização do respetivo autor ou editor da obra.

Na medida em que todas as obras da UC Digitalis se encontram protegidas pelo Código do Direito de Autor e Direitos Conexos e demais legislação aplicável, toda a cópia, parcial ou total, deste documento, nos casos em que é legalmente admitida, deverá conter ou fazer-se acompanhar por este aviso.

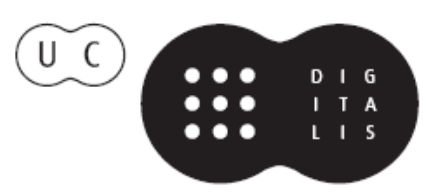




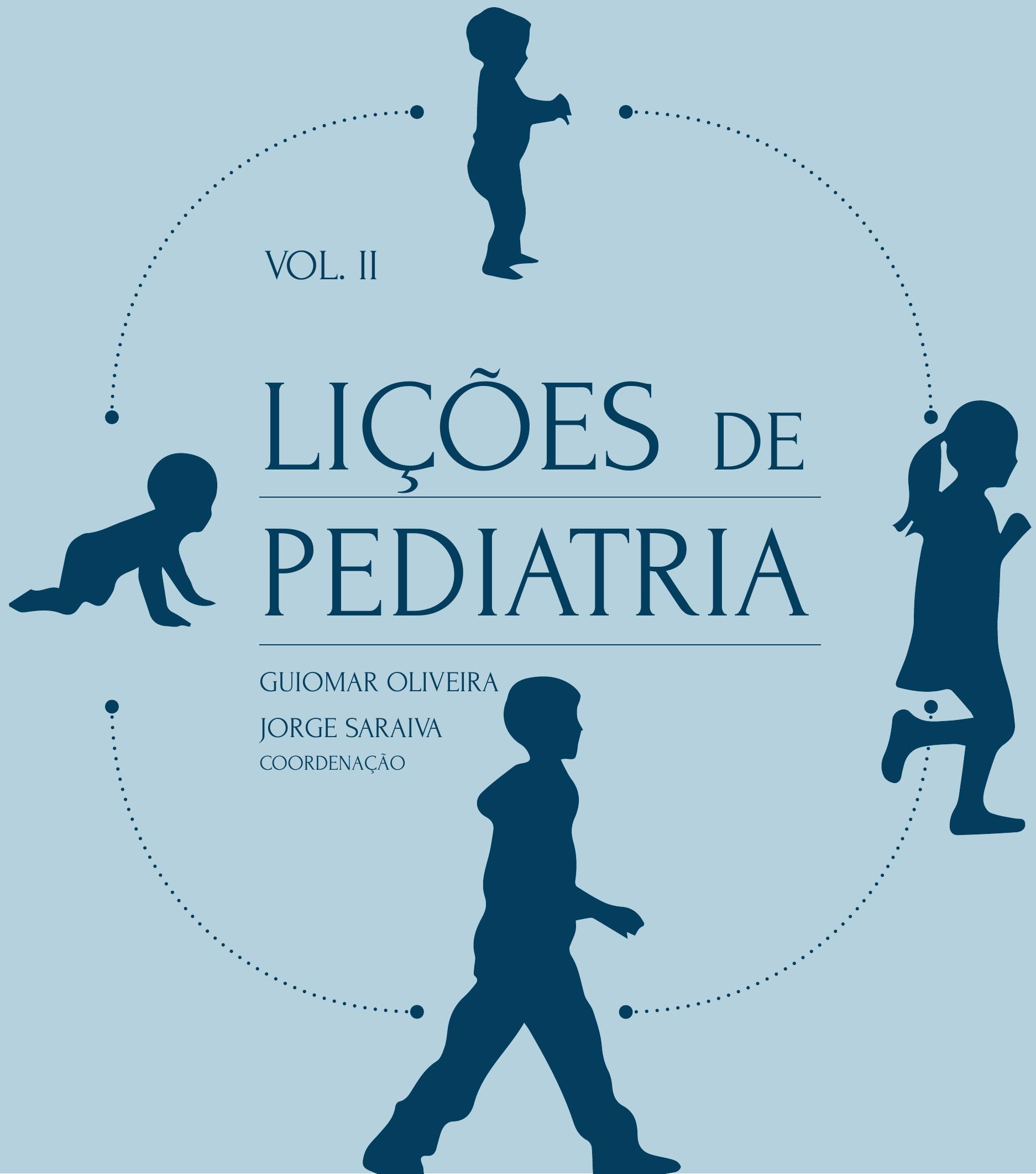


Capítulo 40.

Fenómenos paroxísticos, crises epiléticas e epilepsias
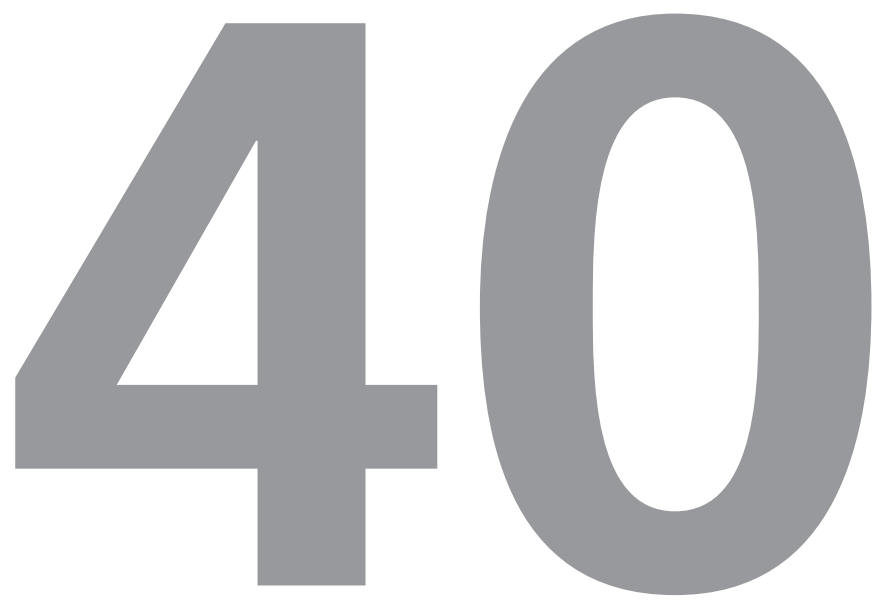

Cristina Pereira

e Conceição Robalo 


\subsection{CONTEXTO}

Fenómenos paroxísticos (FP) são eventos clínicos de instalação súbita, geralmente de curta duração que se podem manifestar por alteração da consciência, do comportamento, movimentos involuntários, alterações do tónus, alterações do padrão respiratório entre outros. Englobam fenómenos fisiológicos (soluços), parassónias, movimentos involuntários, alterações do comportamento, fenómenos psicogénicos (simulações, conversões), disfunções hemodinâmicas (crises vaso-vagais), espasmos de choro, disfunções gastrointestinais (refluxo gastro-esofágico), disfunção respiratória e também crises epiléticas (CE). Os FP podem ou não estar relacionados com descargas elétricas neuronais. Só no caso de CE existe uma disfunção cerebral transitória que leva grupos de neurónios hipersensíveis a fazer súbitas descargas elétricas que se podem traduzir de variadíssimas formas, mudando de doente para doente, ou apresentando diferentes formas no mesmo doente. As CE manifestam-se por alterações da consciência, sintomas motores, sensitivos, autonómicos ou psíquicos, refletindo as diferentes redes neuronais ativadas pelas descargas síncronas e excessivas. O córtex cerebral é a principal origem destas descargas neuronais de $C E$, mas menos frequentemente também se podem originar no tronco cerebral e no sistema tálamo-cortical.

Os FP são muito frequentes em idade pediátrica, apresentando uma incidência de 12,9\% no primeiro ano de vida. Metade destas crianças manifesta inocentes fenómenos fisiológicos e só 9\% apresentam CE e/ou epilepsias. Teremos de ser cuidadosos no diagnóstico diferencial para evitar falsos diagnósticos de epilepsia que poderiam afetar negativamente a vida da criança e da família.

Deve-se saber que CE não é sinónimo de epilepsia. CE na definição da Liga Internacional Contra a Epilepsia (ILAE) é a ocorrência transitória de sinais e/ou sintomas decorrentes de atividade cerebral neuronal anómala, excessiva ou síncrona, enquanto epilepsia se define pela ocorrência espontânea de crises epiléticas. Qualquer pessoa pode ter uma crise e não sofrer de epilepsia, sempre que a disfunção neuronal responsável pela crise em vez de ser espontânea seja provocada por febre, infeção, disfunção metabólica, traumatismo craniano, intoxicação e doenças vasculares.

A ILAE define epilepsia como um problema do cérebro que se caracteriza por uma contínua tendência para gerar crises epiléticas, com todas as suas consequências neurobiológicas, cognitivas, psicológicas e sociais. Esta definição deu origem a um novo conceito: epilepsia é muito mais do que ter crises. Cada vez se torna mais claro que o que no cérebro provoca crises epiléticas, pode provocar também direta ou indiretamente outras disfunções que se irão traduzir em: problemas cognitivos, alterações do comportamento, problemas psiquiátricos e enxaqueca, de entre outros. Neste contexto, é interessante notar que a ILAE recomendou recentemente que o termo «benigno» deixe de ser usado para descrever a epilepsia, por causa do grande número de patologias associado com formas de epilepsias relativamente simples. Em termos clínicos talvez a mensagem mais importante é que não existe «epilepsia apenas». Qualquer doente com epilepsia deve ser visto como alguém que está em risco de apresentar uma série de consequências, 
incluindo problemas cognitivos, problemas do comportamento, depressão, suicídio, e também morte súbita. Não há absolutamente nenhum fundamento para voltar a estigmatizar a epilepsia, mas há todas as razões para se certificar de que médicos, doentes, familiares, bem como educadores e outros estão adequadamente preparados para reconhecer e tratar adequadamente tais dificuldades de adaptação social à medida que surgem.

\subsection{DESCRIÇÃO DO TEMA}

\subsubsection{A primeira crise epilética}

Quatro a 10\% das crianças vão ter uma CE até aos 16 anos. Uma crise (convulsiva ou não convulsiva) pode ocorrer como consequência de um fator precipitante como a febre, infeção do sistema nervoso central (SNC), hipoglicémia, distúrbios hidroeletrolíticos, traumatismo crânio-encefálico (TCE), acidente vascular cerebral (AVC), tumores do SNC, exposição a tóxicos, privação de drogas, entre outras. Excluídos os fatores precipitantes diz-se que estamos perante uma crise não provocada. Recorrência define-se pela ocorrência de nova crise que surge mais de 24 horas após a primeira. O risco de recorrência após a primeira crise não provocada é de $30 \%$. As recorrências surgem em $97 \%$ dos casos com uma mediana de cinco meses (três meses a cinco anos) após a primeira crise não provocada.

Os fatores preditivos de recorrência conhecidos são: crise focal, défice intelectual ou atraso do desenvolvimento psicomotor grave, eletroencefalograma (EEG) com anomalias epileptiformes e neuroimagem cerebral alterada. Não são fatores consistentes preditivos de recorrência a existência de antecedentes pessoais de convulsões febris, antecedentes familiares de epilepsia, défices neurológicos pós-críticos nem estado de mal convulsivo inaugural.

\subsubsection{Atitude perante a primeira crise epilética}

A abordagem da criança com a primeira $C E$ começa pelo " $A B C$ ": A - manter a via aérea permeável; $B$ - manter ventilação - administrar oxigénio e C- avaliar a função cardiocirculatória. Ao mesmo tempo deve ser avaliada a temperatura (exclusão de convulsão febril), a glicémia (para exclusão de convulsões provocadas por hipoglicémia), contextualizar a crise (questionar os familiares sobre as circunstância em que ocorreu) e exame neurológico dirigido (postura, pele nomeadamente exantemas e soluções de continuidade, pupilas e parésias).

O passo seguinte é interromper a crise administrando uma benzodiazepina. Atualmente a primeira escolha recai sobre o midazolam, por via intrabucal, na dose de $\mathbf{0 , 4} \mathrm{mg} / \mathrm{kg} /$ toma, que pode ser repetido se a crise não ceder após cinco minutos. Nas crianças pequenas pode ser administrado o diazepam retal na posologia de $\mathbf{0 . 5} \mathbf{~ m g / k g / t o m a . ~ E n q u a n t o ~ i s s o ~ d e v e m ~ o b t e r - s e ~}$ duas vias endovenosas para eventual administração de fármacos e colheitas séricas. As análises solicitadas devem incluir hemograma, gasometria, ionograma completo, ureia, creatinina, transaminases, doseamento de antiepiléticos (crianças previamente medicadas), pesquisa de tóxicos, culturas/serologias, lactato e amónia (suspeita de doença metabólica). Deve ser realizada punção 
lombar para colheita de líquido cefalorraquidiano (LCR) se a suspeita é de meningite ou encefalite, ou se for em lactentes (nestes é mais difícil a exclusão clínica das referidas entidades). A tomografia computorizada crânio-encefálica (TC-CE) deve ser ponderada se a criança não recuperar o estado de consciência, se existirem sinais focais persistentes, sinais de hipertensão intracraniana (neste caso realizar antes da punção lombar) ou se a etiologia for desconhecida.

No caso de crise sintomática aguda, para além do tratamento da crise convulsiva deve-se proceder ao tratamento causal: corrigir-se a hipoglicémia com glicose a 10\%, na dose de $5 \mathrm{ml} /$ $\mathrm{kg}$, por via endovenosa, tratar-se a infeção virusal ou bacteriana (aciclovir ou antibióticos respetivamente), administrar-se naloxona em caso de intoxicação por narcóticos, ou dexametasona no edema cerebral.

O eletroencefalograma (EEG) é o exame de eleição para o esclarecimento de eventual causa epilética após uma crise não provocada. Deve ser solicitado para apoiar o diagnóstico clínico de epilepsia e classificar a epilepsia e/ou o síndrome epilético. Quando indicado deve ser realizado assim que possível (primeiras 24 a 48 horas após a primeira crise). Está sempre indicada a sua realização após a segunda crise não provocada ou se estiverem presentes fatores de risco de recorrência.

\subsubsection{Orientações gerais}

Após episódio de primeira CE não provocada deverá ser prescrita e ensinada a administração em sos de diazepam retal ou midazolam intrabucal. Nos casos em que está indicado realizar EEG deverá sempre ser pedida consulta de Pediatria, ou preferencialmente de Neuropediatria, para futura orientação.

\subsubsection{Crises epiléticas/epilepsia}

\subsubsection{Epidemiologia}

As crises epiléticas são um dos sintomas neurológicos mais frequentes em idade pediátrica. A epilepsia afeta em países desenvolvidos $4 \%$ das crianças e este número duplica em países não desenvolvidos. A incidência varia com a idade, apresentando o valor mais alto durante o primeiro ano de vida: 100 a 200/100.000, decaindo para 60/100.000 durante a adolescência. A prevalência aumenta com a idade: aos 7 anos é de 2,3/1.000 e aos 10 anos é de 4 a 6/1.000.

\subsubsection{Diagnóstico diferencial}

No diagnóstico diferencial de todos estes fenómenos paroxísticos teremos de considerar

\section{três questões fundamentais:}

1.são ou não são fenómenos epiléticos?

2.em caso de se tratar de fenómenos epiléticos, de que tipo de crises se trata?

3.que etiologia apresentam e em que tipo de síndrome ou doença epilética se englobam?

Em 2006 a ILAE também reviu o esquema diagnóstico para pessoas com crises epiléticas e epilepsia e considerou cinco alíneas para resolver a questão diagnóstica (quadro 1).

Face a um doente com crises epiléticas em vez de se pensar unicamente em "tratar" será mandatório tentar diagnosticar os síndromes e 
EIXO 1 Descrição detalhada das crises.

EIXO 2 Definir o tipo de crise pela classificação da ILAE.

EIXO 3 Definir o tipo de síndrome (metade ocorrem até à idade escolar).

EIXO 4 Definir o diagnóstico etiológico do síndrome (genético, metabólico, estrutural).

EIXO 5 Definição de incapacidade (opcional).

Quadro 1. Esquema diagnóstico para pessoas com crises epiléticas e com epilepsia - ILAE.

as patologias que as causam. Só assim se poderá avançar para um tratamento adequado, mais eficaz e um prognóstico definido.

A avaliação clínica é frequentemente suficiente para estabelecer uma hipótese diagnóstica correta, com base: na descrição dos episódios, na identificação dos possíveis fatores precipitantes, na distribuição circadiana dos episódios, no cuidadoso exame clínico, que no caso das crianças tem sempre de ser acompanhado de uma avaliação do neurodesenvolvimento. É muito importante determinar se existe história familiar de epilepsia nos familiares diretos.

Noutros casos a avaliação clínica é insuficiente. O uso de "vídeo caseiro" pode ser muito útil na avaliação inicial destas crianças com FP. Não devemos esquecer que a primeira crise é frequentemente uma forma de apresentação de outras patologias: infeciosas, metabólicas, tóxicas e também patologias estruturais do SNC; pelo que estudos bioquímicos, plasmáticos e do LCR, metabólicos, toxicológicos e imagiológicos terão sempre de ser considerados após a colheita da história clínica e da observação.

O EEG ou Vídeo EEG é considerado o exame auxiliar de diagnóstico mais importante para a caraterização e diagnóstico diferencial de FP epiléticos e FP não epiléticos. Nas crianças os FP quando acontecem, apresentam geralmente uma grande frequência pelo que mais facilmente podem ser gravados durante o Vídeo-EEG. Em crianças, que adormecem facilmente no laboratório, o EEG poderá apresentar melhor sensibilidade se incluir um período de vigília e um período de sono atingindo então uma sensibilidade de $80 \%$. A repetição de um EEG de vigília e sono eleva a sensibilidade no diagnóstico de epilepsia para 92\%. Resumindo: o EEG ou Vídeo EEG serve para distinguir entre episódios clínicos como crises epiléticas ou FP não epiléticos, para ajudar a definir o tipo de crise e de síndrome epilético e serve para corroborar o diagnóstico de epilepsia sugerido pela clínica, mas raramente para o excluir.

\subsubsection{Classificação de crises epiléticas}

Do ponto de vista clínico é muito importante que os técnicos utilizem uma terminologia uniforme que permita a comunicação, a investigação e a compreensão destes fenómenos. Nasceu assim a necessidade de classificar crises. Podem classificar-se crises de acordo com a localização da descarga neuronal, as manifestações clínicas, a etiologia, a idade de início, e as manifestações eletroencefalográficas. Esta categorização é essencial para estudos epidemiológicos, ensaios terapêuticos, e para a investigação biológica da epilepsia. Em 1981 surge a Classificação das CE da ILAE, que tem vindo a ser revista, datando de 2010 a última revisão (figura 1), em que a 


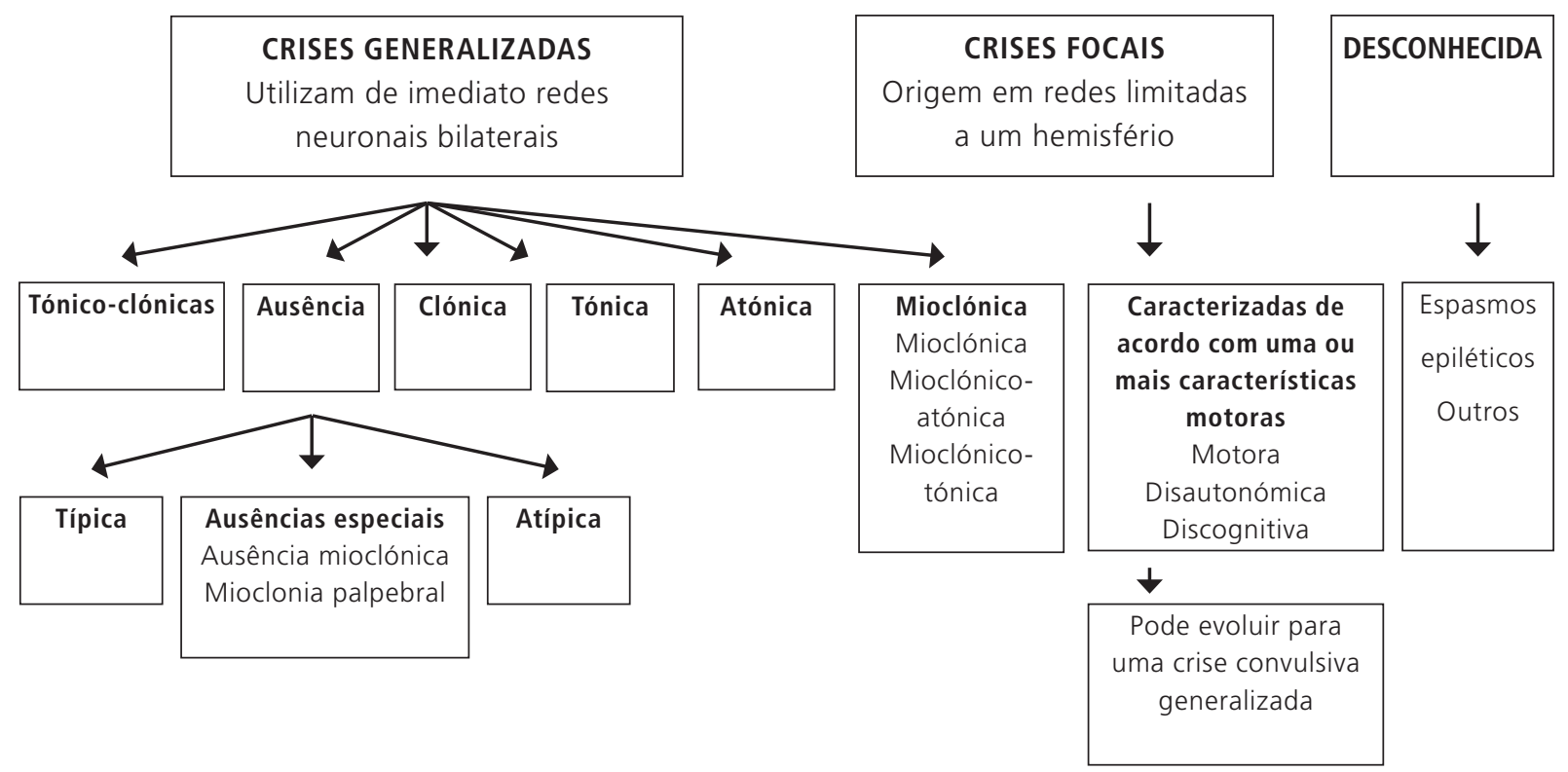

Figura 1. Classificação das crises epiléticas proposta pela ILAE, 2010.

divisão fundamental continua a ser entre crises focais e generalizadas, tendo em vista a origem/ localização da descarga neuronal.

\subsubsection{Síndromes epiléticos}

A ILAE reconhecendo a limitação da classificação das CE desenvolveu um projeto mais ambicioso para uma nova classificação, que agrega determinados tipos de crise, fatores desencadeantes, horário, idade de início, localização anatómica, etiologia e prognóstico, constituindo síndromes. Os síndromes distinguem-se da doença epilética porque esta junta às características já descritas, etiologia e prognóstico específicos. Atualmente na proposta de classificação da ILAE de 2010, os síndromes agrupam-se pela idade de início (figura 2). Neste texto trataremos com especial atenção as Convulsões Febris (CF), o Síndrome de West (SW), a Epilepsia Benigna com Pontas Centrotemporais (BECTS), a Epilepsia de Ausências Infantis (EAI) e a Epilepsia Mioclónica Juvenil (EMJ).

\subsubsection{Convulsões febris}

Convulsões febris (CF) são os síndromes eletroclínicos mais frequentes na infância. CF são definidas pela ILAE como "uma convulsão em associação com uma doença febril, na ausência de uma infeção do SNC ou desequilíbrio agudo eletrolítico em crianças com mais de um mês de idade, sem convulsões apiréticas prévias". A temperatura deve ser superior a $38,4^{\circ} \mathrm{C}$. Não necessita de estar elevada exatamente no momento da crise, mas sim num período de 24 horas antes ou depois da convulsão. CF são mais comuns entre os seis meses e cinco anos de idade, com um pico de incidência aos 18 meses. São CF simples se forem tónico-clónicas, autolimitadas, de curta duração 


\section{SÍNDROMES ELETROCLÍNICOS AGRUPADOS POR IDADE DE INÍCIO*}

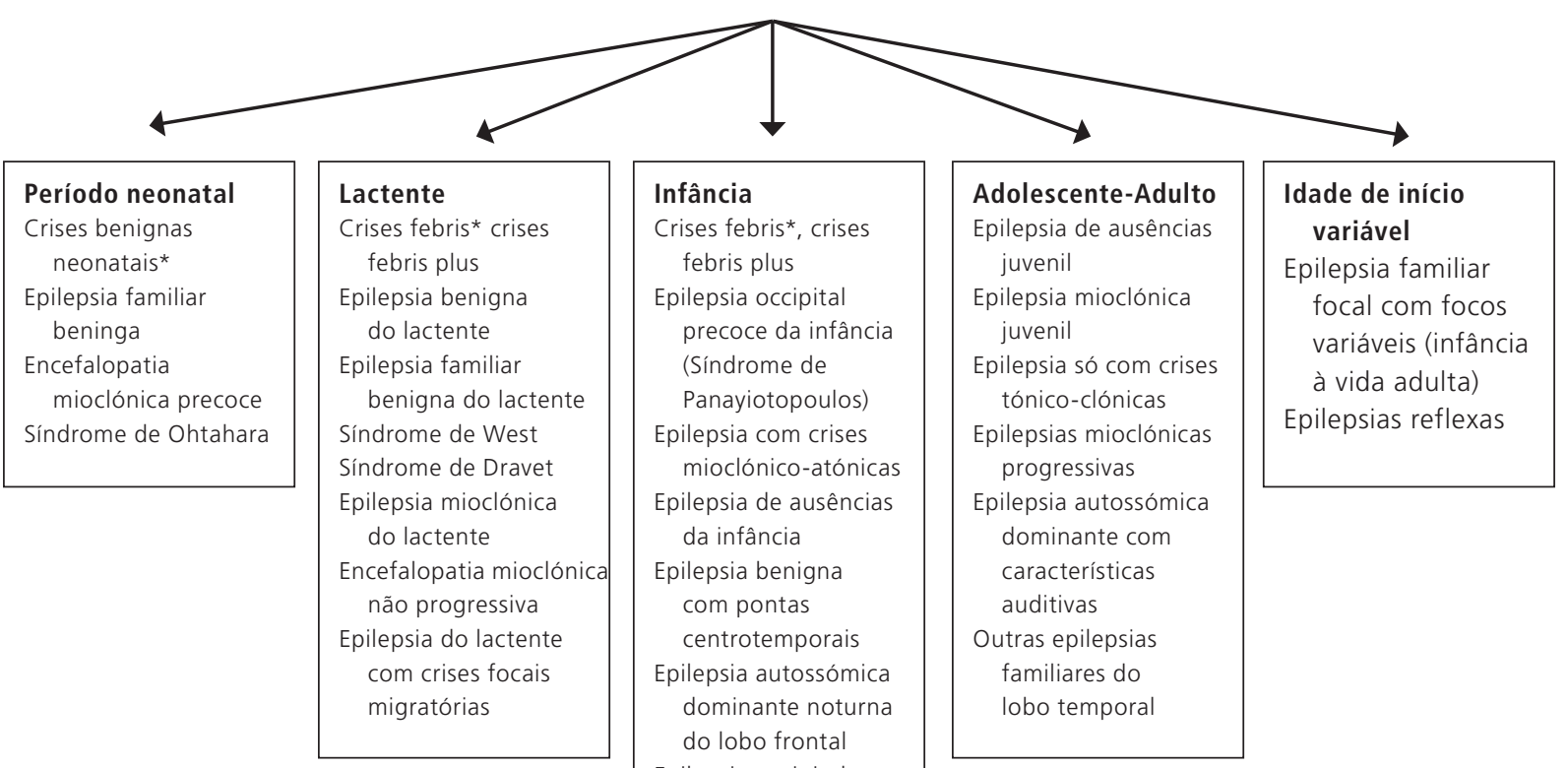

Epilepsias distintas/síndromes Cirúrgicos

Epilepsia mesial do lobo temporal com

esclerose do hipocampo

Síndrome de Rasmussen

Crises geláticas com hamartoma hipotalâmico

Epilepsia hemiconvulsão-hemiplegia

\section{Epilepsia occipital} de início tardio da infância (tipo Gastaut)

Epilepsia com ausências mioclónicas

Síndrome de LennoxGastaut

Encefalopatia epilética com pontaonda contínua durante o sono

Síndrome de LandauKleffner

\section{Epilepsias não sindrómicas* *}

Epilepsia atribuídas a causa estrutural/ metabólica

- Malformações do desenvolvimento cortical (hemimegalencefalia, heterotopias, entre outras)

-Síndromes neurocutâneos (Complexo Esclerose Tuberosa, Sturge-Weber, e outros) -Tumor, infeção, trauma, angioma, insulto pré ou perinatal, acidente vascular cerebral

Epilepsias de causa desconhecida

Figura 2. Classificação dos síndromes eletroclínicos e outras epilepsias proposta pela ILAE, 2010.

Legenda: *Esta organização dos síndromes não reflete a etiologia; Não tradicionalmente diagnosticados como epilepsia;

**Formas de epilepsia sem critérios específicos para síndromes.

(inferior a 15 minutos), sem défice neurológico pós-crítico, e se não se repetirem nas 24 horas seguintes. As CF são complexas se tiverem uma duração mais longa (superior a 15 minutos), características focais ou se se repetirem dentro de 24 horas (várias convulsões). Status febril, pode ser uma crise única de longa duração, superior a
30 minutos, ou uma série de curtas convulsões, sem recuperação da consciência entre as mesmas. CF devem ser distinguidas das «crises com febre». Estas últimas incluem qualquer convulsão, em qualquer criança, com febre de qualquer etiologia. Consequentemente, crianças com meningite ou encefalite, não têm CF, mas têm "crises com 
febre". Entre os quatro meses e cinco anos de idade, $2 \%$ a $4 \%$ de todas as crianças terão pelo menos uma CF, geralmente breve. Estas crises aterrorizam os pais, mas não estão associadas a danos cerebrais nas crianças. Em $40 \%$ das crianças com a primeira CF regista-se CF recorrentes, mas a epilepsia desenvolve-se apenas em 2\% a 4\% delas. A história familiar de CF e a idade de início inferior a um ano são considerados os únicos fatores de risco significativos para o desenvolvimento de epilepsia nestas crianças.

No diagnóstico diferencial das CF a questão mais importante é excluir uma infeção do SNC. Os sinais de irritação meníngea podem ser difíceis de avaliar numa criança pequena. Justifica-se um exame neurológico completo e se houver suspeita clínica de infeção do SNC, a punção lombar deve ser realizada. No caso de CF simples não há necessidade de efetuar EEG. O EEG será de considerar em crianças com CF complexas, prolongadas em que se possa suspeitar de outro síndrome epilético como o síndrome de Dravet. Este síndrome associa crises polimórficas, inicialmente $C F$, depois CF clónicas precoces, mioclonias, ausências e crises focais complexas com deterioração neurocognitiva. Está associado a mutações no gene - Sodium Voltage-Gated Channel Alpha Subunit 1 - SCN1A.

Sobre o tratamento das CF considera-se o tratamento agudo da convulsão e o tratamento antipirético. A profilaxia de rotina tornou-se menos popular por causa das preocupações com os efeitos colaterais dos medicamentos usados, especialmente do fenobarbital e da falta de qualquer benefício comprovado na recorrência de novas CF e no desenvolvimento de epilepsia posterior. No tratamento agudo das CF utilizam-se benzodiazepinas, diazepam e midazolam, por via retal, intrabucal e endovenosa. São usadas para controlar rapidamente as CF que não cessam espontaneamente, como no tratamento das crises epiléticas apiréticas. Não está documentado que tratamento antipirético durante as doenças febris, reduza a taxa de recorrência das CF. Os antipiréticos devem ser administrados para o conforto da criança febril, mas não como medida para reduzir a taxa de recorrência de CF.

\subsubsection{Síndrome de West (SW)}

A associação de "espasmos infantis e regressão do desenvolvimento" foi descrita em 1841 pelo Dr. West ao observar os espasmos no seu próprio filho. Em 1950 Gibbs e Gibbs descreveram a tríade: espasmos infantis, hipsarritmia (padrão eletroencefalográfico caraterístico-traçado caótico, não rítmico, assíncrono, desorganizado, com atividade caraterizada por ondas lentas de alta voltagem, de associação variável com pontas difusas ou multifocais) e atraso e/ou regressão nas aquisições do desenvolvimento psicomotor. Atualmente, a ILAE classifica os espasmos como crises epiléticas "de causa desconhecida", por não apresentarem evidência clara de serem ou focais ou generalizadas e o Síndrome de West como um síndrome epilético do lactente em que a grave desorganização epileptiforme do funcionamento cerebral causa progressiva regressão do neurodesenvolvimento. O SW apresenta uma incidência de 3 a 4,5/10.000 nados-vivos. Setenta por cento dos casos apresenta etiologias bem definidas: doença vascular perinatal e encefalopatia hipóxico-isquémica, anomalias congénitas cerebrais, doenças neurocutâneas (complexo esclerose tuberosa), displasias corticais, cromossomopatias, infeções congénitas ou adquiridas, disfunções metabólicas e doenças mitocondriais de entre outras. Clinicamente carateriza-se 
por início entre os três e os 12 meses de idade e predomínio no sexo masculino. Os espasmos são contrações súbitas, breves da musculatura axial e dos membros. Aparecem em clusters, em flexão, em extensão ou mistos. Podem ser simétricos ou assimétricos, por vezes associados a outro tipo de crises. Acompanham-se de grande irritabilidade e desconforto do bebé, que frequentemente deixa de fazer contacto visual e de sorrir. O EEG tem um padrão específico quer nas crises, quer entre crises - padrão hipsarrítmico, pelo que o diagnóstico de certeza não é difícil. A sua suspeita implica a imediata referenciação a uma consulta de epilepsia - neuropediatria num centro de referência. O protocolo de investigação e terapêutica, dada a sua complexidade e importância, para minimizar graves implicações no neurodesenvolvimento, só deverá ser efetuado numa consulta de referência. Neste síndrome todas as opções terapêuticas são de considerar: farmacológicas (antiepiléticos, corticoides), dietéticas (dieta cetogénica), vitamínicas (vitamina B6) e cirúrgicas. Mesmo assim o prognóstico do SW, nos casos "sintomáticos", será sempre o prognóstico da entidade patológica responsável, geralmente apresentando apenas 5 a $12 \%$ de casos com desenvolvimento psicomotor normal. Nos casos idiopáticos ou criptogénicos, 15 a 30\% atingem desenvolvimento psicomotor normal. São fatores de bom prognóstico o desenvolvimento normal antes do aparecimento do SW, a simetria dos espasmos e a manutenção em EEG de um padrão de sono adequado.

\subsubsection{Epilepsia benigna}

com pontas centrotemporais

A epilepsia benigna da infância ou rolândica, designada na nova classificação como epilepsia benigna com pontas centrotemporais (BECTS) é a epilepsia focal mais comum na infância, representando 8 a 20\% das epilepsias em idade pediátrica. De etiologia genética, ocorre em crianças com desenvolvimento e exame neurológico normais. Inicia-se entre os sete e os dez anos de idade, com um ligeiro predomínio no sexo masculino. Clinicamente carateriza-se por crises com início no sono em que ocorrem sintomas sensoriomotores faciais unilaterais (clonias da região peribucal ou da hemiface), manifestações orofaringolaríngeas (parestesias da língua, ruídos laríngeos), impossibilidade de articulação de palavras e hipersalivação. A consciência encontra-se preservada mas em alguns casos as crises podem generalizar. O EEG é típico, apresentando pontas trifásicas na região centrotemporal muito sensibilizadas pelo sono. A ressonância crânio-encefálica (RM-CE) é normal e não está recomendada a sua realização na presença de clínica e EEG característicos. As crianças com BECTS só necessitam de terapêutica antiepilética, se as crises forem diurnas, frequentes e se em termos sociofamiliares se manifestarem de forma disruptiva. O prognóstico das crises é bom com remissão habitualmente pelos 13 anos, mas 30\% das crianças apresenta dificuldades escolares. Existem com menor frequência outras epilepsias benignas focais na infância, nomeadamente a epilepsia occipital precoce (síndrome de Panayiotopoulos) e a epilepsia occipital de início tardio (tipo Gastaut).

\subsubsection{Epilepsia de ausência da infância}

A epilepsia de ausência da infância é uma epilepsia generalizada que se inicia pelos cinco a sete anos de idade, com predomínio no sexo feminino. De etiologia genética, merece 
reconhecimento precoce para o controlo das crises e minimizar compromissos do rendimento escolar. As crises, inúmeras ao dia (dezenas), caraterizam-se por uma alteração/perda de consciência de início e fim abruptos com duração de quatro a vinte segundos, em que a criança não responde e modifica a sua atividade. Podem ocorrer mioclonias palpebrais (pestanejo) ou automatismos associados (oromandibulares, extensão da cabeça). O EEG apresenta um padrão típico: descargas generalizadas de ponta-onda a $3 \mathrm{~Hz}$, sensibilizadas pela prova de hiperpneia. É uma epilepsia que necessita sempre de tratamento antiepilético. O valproato de sódio em monoterapia ou a sua associação com a etossuximida controlam as crises em $80 \%$ das crianças. O prognóstico é bom com remissão habitualmente pelos 12 anos de idade.

\subsubsection{Epilepsia mioclónica juvenil (EMJ)}

A EMJ é uma epilepsia generalizada idiopática que se inicia pelos 14 a 15 anos, e é de etiologia genética. Cursa inicialmente com mioclonias (em 100\% dos casos) de predomínio ao despertar e dos membros superiores e mais tarde surgem crises tónico-clónico generalizadas (em 90\% dos casos). Podem ocorrer ausências em 30\% dos jovens. São fatores precipitantes reconhecidos das crises a privação de sono, o consumo de álcool, a fadiga e os estímulos luminosos. O desenvolvimento neurocognitivo, o exame neurológico e a neuroimagem são normais. O EEG típico apresenta ponta-onda e/ou poliponta-onda irregular generalizada a 4 a $6 \mathrm{~Hz}$ e fotossensibilidade num terço dos casos. Habitualmente ocorre normalização do EEG após terapêutica e compliance adequadas. O prognóstico sob antiepilético é bom, com controlo das crises e normalização do EEG. Verifica-se necessidade de terapêutica antiepilética a longo prazo ocorrendo recidiva em $80 \%$ dos jovens após suspensão do tratamento.

\subsubsection{Orientações gerais}

Existem recomendações para a investigação e tratamento da epilepsia em idades pediátrica. As normas do National Institute for Health and Care Excellence (NICE) recomendam que todas as crianças e jovens que tiveram uma primeira crise apirética devam ser consultadas o mais rapidamente possível por um Pediatra com conhecimentos na área de epilepsia, para assegurar um diagnóstico precoce e preciso e início da terapia de acordo com as suas necessidades.

Epilepsias que se iniciem em crianças até ao início da idade escolar, que não tenham diagnóstico sindrómico específico, ou não tenham as suas crises controladas, ou revelem alteração do seu exame neurológico, ou que apresentem lesão identificada em estudo imagiológico deverão ser referenciadas a Centros Especializados de Epilepsia.

Deverá efetuar-se estudo imagiológico sempre que a epilepsia tenha início antes dos dois anos, sempre que haja crises focais (exceto na BECTS) e sempre que a epilepsia se revele fármaco-resistente.

Deverão também referenciar-se crianças e jovens para uma consulta de epilepsia quando o diagnóstico de epilepsia não é seguro, quando não se obtém rapidamente o controlo das crises, quando há outras alterações neurológicas associadas ou quando surgem complicações com o tratamento. 


\subsubsection{Estado de mal}

O estado de mal ocorre em 17 a 23/100.000 crianças por ano. Apresenta uma mortalidade de cerca de 3.4 a 6\% dependendo da etiologia.

Define-se pela ocorrência de CE de duração superior a 30 minutos ou crises repetidas sem recuperação do estado de consciência. Pode ser convulsivo quando há clínica motora evidente (i.e. movimentos clónicos), ou não convulsivo quando as manifestações motoras são escassas e apenas são evidentes alterações do comportamento e/ou da consciência, com tradução no EEG. É considerado refratário se a(s) crise(s) persiste(m) após administração adequada de dois fármacos antiepiléticos de acordo com o protocolo.

\subsubsection{Atitude perante um estado de mal}

Uma criança admitida no serviço de urgência em crise convulsiva é considerada como estando em estado de mal convulsivo até prova em contrário. Deve atuar-se como se tratando de um estado de mal se a convulsão ou crise persiste por mais de cinco minutos. Ter em mente que quanto mais tempo se aguardar até usar o primeiro fármaco, mais difícil será, e mais fármacos vão ser necessários, para controlar a crise. As convulsões prolongadas desencadeiam alterações sistémicas e do SNC. A nível sistémico, na primeira fase ocorrem alterações adaptativas com taquicardia, hipertensão, aumento do fluxo sanguíneo cerebral, hipertermia e hiperglicémia o que permite satisfazer o aumento das necessidades metabólicas da crise prolongada. Com a continuação da crise, esgotam-se os mecanismos compensatórios ocorrendo acidose metabólica, hiperlactacidémia, bradicardia, hipotensão, hipóxia e lesão neuronal. A nível do SNC ocorre diminuição dos neurotransmissores inibitórios (ácido gama aminobutírico-GABA) e aumento dos neurotransmissores excitatórios (glutamato), a par de uma reorganização sinática com perda de interneurónios GABAérgicos (inibitórios) e aumento dos neurónios excitatórios.

De uma forma geral, dever-se-á aplicar o protocolo para o estado de mal epilético em idade pediátrica da Sociedade Portuguesa de Neuropediatria: http://neuropediatria.pt/sites/ default/files/tratamento_estado_mal_epileptico_spnp.pdf.

O primeiro fármaco a utilizar é uma benzodiazepina (midazolam ou diazepam na mesma dose que para outra crise) podendo ser repetida após cinco minutos. Se não ceder em cinco minutos, administrar fenitoína 15 a 20 mg/ kg/dose por via endovenosa em 20 minutos. Se não se reverter a convulsão, deverá ser instituído midazolam na dose de $0.15 \mathbf{~ m g / ~}$ kg endovenoso em bólus, seguido de perfusão. A última prescrição só deverá ser considerada na proximidade de uma Unidade de Cuidados Intensivos Pediátricos. Outros fármacos antiepiléticos também eficazes são: valproato de sódio em perfusão (estado de mal de ausências, estado de mal mioclónico ou estado de mal refratário), levetiracetam em perfusão, e piridoxina (300 mg via endovenosa) que deverá sempre ser administrada em crianças com idade inferior a três anos (como prova terapêutica na epilepsia dependente de piridoxina que é uma causa metabólica rara mas tratável). O tratamento da causa subjacente é semelhante ao da primeira crise. 


\subsubsection{Tratamento da epilepsia}

O tratamento da epilepsia engloba tratamento farmacológico e não farmacológico. O tratamento farmacológico considera fármacos antiepiléticos (FAE), corticóides (situações em que a epilepsia se acompanha de encefalopatia) e neuromodulação (situações de epilepsia/ encefalopatia autoimune). Os FAE diminuem mas não eliminam o risco de recorrência e não têm influência na remissão a longo prazo da epilepsia. O antiepilético ideal seria eficaz em múltiplos tipos de crises, não agravaria qualquer outro tipo de crise, não teria efeitos secundários, teria uma farmacocinética previsível e não deveria interagir com outros fármacos. O tratamento não farmacológico engloba a dieta cetogénica, estimulação do nervo vago e cirurgia da epilepsia.

Existem casos selecionados com orientações terapêuticas bem definidas: vitamina B6 (piridoxina) para a epilepsia dependente de piridoxina; dieta cetogénica na epilepsia secundária a défice do transportador da glicose cerebral (GLUT1) e estimulação do nervo vago em epilepsias fármaco-resistentes especialmente em crises com generalização secundária.

Para estudo pré-cirúrgico, devem ser orientados os seguintes casos: recém-nascidos e lactentes com epilepsia; criança até aos dois anos de idade com epilepsias não controladas, crianças com RMCE, com ou sem lesão, sem controlo terapêutico e síndromes específicos: West sintomático, Rasmussen (encefalite provavelmente imunomediada que afeta um hemisfério cerebral de forma devastadora originando crises focais refratárias e défices neurológicos contralaterais) e hemissíndromes (por exemplo hemimegalencefalia).
Antes de iniciar terapêutica com FAE o médico deve:

1. Estar seguro do diagnóstico de epilepsia (exclusão de fenómenos paroxísticos não epiléticos).

2. Estar presente epilepsia ou síndrome epilético que necessite de tratamento (implica conhecer a frequência das crises e a sua gravidade, os fatores precipitantes, a probabilidade de remissão espontânea e o binómio risco-benefício dos FAE).

3. Conhecer os FAE mais adequados para o tipo de epilepsia e para a criança a tratar (existem fármacos que agravam alguns tipos de epilepsia, como por exemplo a carbamazepina e derivados, fenitoína e lamotrigina agravam crises mioclónicas).

4. Conhecer as doses recomendadas no início da terapêutica, de titulação e de manutenção do fármaco a utilizar (introduzi-lo em doses progressivamente crescentes até dose terapêutica desejada, devendo ser mantida a dose mínima eficaz).

5. Em caso de insucesso dos FAE deve-se questionar a compliance terapêutica ou a existência de malabsorção (pode ser confirmado pela existência de níveis infraterapêuticos na dosagem sérica, de preferência avaliados imediatamente antes da toma do fármaco). Só após doses terapêuticas máximas, será de considerar a substituição do FAE ou associação de outro fármaco.

6. Conhecer os riscos da politerapia (mais efeitos adversos, mais interações 
medicamentosas, dificuldade em avaliar a eficácia de um fármaco e pior compliance).

7. Uma vez iniciados os FAE estes geralmente, só deverão ser interrompidos de forma gradual (semanas a meses) após dois anos sem crises.

Os FAE mais usados em idade pediátrica, dose de manutenção, indicações gerais, efeitos adversos e precauções mais frequentes são os seguintes:

1. Levetiracetam 20 a $40 \mathrm{mg} / \mathrm{kg} / \mathrm{dia}$ - epilepsias focais e generalizadas. Efeitos adversos mais comuns - irritabilidade, alterações de comportamento e psicose. Precaução na insuficiência renal.

2. Valproato de sódio 20 a $40 \mathrm{mg} / \mathrm{kg} / \mathrm{dia}-$ epilepsias focais e generalizadas. Efeitos adversos mais comuns - náuseas, dispepsia, aumento de peso, tremor. Precaução nas doenças mitocondriais, insuficiência hepática e discrasias sanguíneas.

3. Oxcarbazepina 20 a 40 mg/kg/dia - fármaco de eleição em epilepsias focais. Efeitos adversos mais comuns - cefaleia, náusea, ataxia, diplopia, hiponatrémia. Reação idiossincrática - toxidermia e síndrome de Stevens-Johnson. Contraindicado nas epilepsias generalizadas com mioclonias que podem ser agravadas.

4. Benzodiazepinas (clobazam e clonazepam) - habitualmente usadas em combinação com outro fármaco. Efeitos adversos mais comuns - sedação e diminuição das capacidades cognitivas. Risco de tolerância com o uso prolongado.
Não está recomendada fazer avaliação analítica prévia de rotina, só apenas se clinicamente justificada.

\subsection{FACTOS A RETER}

Tal como já escrevemos atrás, sofrer de epilepsia é muito mais do que ter crises epiléticas. $O$ desafio do diagnóstico e tratamento duma epilepsia em idade pediátrica, que se desenvolve durante o período fundamental do desenvolvimento cerebral é não só tratar crises, mas minimizar as comorbilidades cognitivas com importantes dificuldades de aprendizagem, as alterações do comportamento com elevada prevalência de hiperatividade e défice de atenção, o autismo e a patologia psiquiátrica com depressão e psicose que apresentam neste contexto uma frequência superior à da população em geral.

Mesmo em crianças com epilepsias consideradas "benignas" estas fazem-se acompanhar de um importante número de comorbilidades. Crianças com epilepsia apresentam um risco 2,6 vezes mais elevado de desenvolver comorbilidades psiquiátricas e/ou académicas quando comparadas com um grupo com uma crise única.

\section{Leitura complementar}

Consensos da Sociedade Portuguesa de Neuropediatria. Tratamento do estado de mal epiléptico em idade pediátrica. Acta Pediatr Port 2007; 38(4): 163-8.

The National Institute for Health and Clinical Excellence (NICE)-guideline form UK 2004.

Berg AT, Berkovic SF, Brodie MJ, Buchhalter J, Cross JH, van Emde Boas W, Engel J, French J, Glauser TA, Mathern GW, Moshé SL, Nordli DR, Plouin P, Scheffer IE. Revised 
terminology and concepts for organization of seizures and epilepsies: Report of the ILAE Commission on Classification and Terminology, 2005-2009. Epilepsia 2010; 51: 676-685.

Friedman MJ, Sharieff GQ. Seizures in children. Pediatr Clin North Am 2006; 53(2): 257-77.

Pereira C, Resende C, Fineza I, Robalo C. A 15-year follow-up of first unprovoked seizures: a prospective study of 200 children. Epileptic Disord 2014;16 (1):50-5.

Engel J. ILAE classification of epilepsy syndromes. Epilepsy Res 2006; 70(1):S5-10.

Panayiotopoulos, CP. Epileptic encephalopathies in infancy and early childhood. In: A clinical guide to Epileptic Syndromes and their treatment. Oxford 2010.

Chin RF, Neville BG, Peckham C, Bedford H, Wade A, Scott RC; NLSTEPSS Collaborative Group. Incidence, cause, and short-term outcome of convulsive status epilepticus in childhood: prospective population-based study. Lancet 2006; 15; 368(9531): 222-9. 